\title{
Thimerosal reveals calcium-induced calcium release in unfertilised sea urchin eggs
}

\author{
Alex McDougall, Isabelle Gillot and Michael Whitaker \\ Department of Physiology, University College, London, London, UK
}

\section{Summary}

The fertilisation calcium wave in sea urchin eggs triggers the onset of development. The wave is an explosive increase in intracellular free calcium concentration $\left(\left[\mathrm{Ca}_{1}^{2+}\right]\right)$ that begins at the point of sperm entry and crosses the egg in about $20 \mathrm{~s}$. Thimerosal is a sulphydryl reagent that sensitises calcium release from intracellular stores in a variety of cell types. Treatment of unfertilised eggs with thimerosal causes a slow increase $\left[\mathrm{Ca}_{1}^{2+}\right]$ that results eventually in a large, spontaneous calcium transient and egg activation. At shorter times after thimerosal treatment, egg activation and the calcium transient can be triggered by calcium influx through voltage-gated calcium channels, a form of calcium-induced/calcium release (CICR). Thimerosal treatment also reduces the latency of the fertilisation calcium response and increases the velocity of the fertilisation wave. These results indicate that thimerosal can unmask CICR in sea urchin eggs and suggest that the ryanodine receptor channel based CICR may contribute to explosive calcium release during the fertilisation wave.

Keywords: Calcium wave, Calcium-induced calcium release (CICR), Fertilisation, Inositol trisphosphate receptor, Ryanodine receptor

\section{Introduction}

The fertilising sperm causes a wave of calcium release in sea urchin eggs that starts at the site of sperm entry (for a review, see Whitaker \& Swann, 1993). Calcium waves of this sort seem not only to be a common feature at fertilisation (Jaffe, 1983) but also in cell signalling in a wide variety of somatic cells (Berridge \& Galione, 1988; Jacob, 1990). An explosive, autocatalytic mechanism must underlie the wave (Kacser, 1955) and a number have been suggested. One variant involves the phosphoinositide messenger system; it is strongly activated at fertilisation (Turner et al., 1984; Whitaker \& Irvine, 1984; Ciapa et al., 1992). We suggested that calcium release induced by the calcium-mobilising messenger inositol trisphosphate $\left(\mathrm{InsP}_{3}\right)$ is potentiated by calcium-stimulated production of further InsP $\mathrm{P}_{3}$ via calcium-dependent phosphoinositi-

All correspondence to: Michael Whitaker, Department of Physiology, University College London, Gower Street, London WC1E 6BT, UK. Telephone: +4471 388 9304. Fax: +44713883892 . dase C (Whitaker \& Irvine, 1984; Whitaker \& Aitchison, 1985); this mechanism has received some support from experiments on somatic cells (Meyer \& Stryer, 1988). Another plausible mechanism suggested from experiments on somatic cells is sensitisation of the InsP $\mathrm{P}_{3}$-gated calcium channel by increases in intracellular free calcium concentration $\left[\mathrm{Ca}_{1}^{2+}\right]$ (Bezprovzanny et al., 1991; Finch et al., 1991). Unfortunately, though heparin, a blocker of InsP $\mathrm{P}_{3}$-induced calcium release, increases the latency of the fertilisation calcium response, it does not affect the magnitude or rate of rise of the fertilisation calcium transient in sea urchin eggs (Crossley et al., 1991), thus setting them apart from frog and hamster eggs, in which Ins $\mathrm{P}_{3}$ antagonists block the fertilisation calcium wave (Miyazaki et al., 1992; Whitaker \& Swann, 1993).

Another potentially explosive mechanisma that might explain the fertilisation wave is the classic phenomenon of calcium-induced calcium release (CICR), first observed in cardiac muscle (Endo, 1977; Fabiato, 1985). Classic CICR is a property of the ryanodine receptor, a calcium-release channel with a very strong structural similarity to the $\mathrm{InsP}_{3}$ receptor/ 
release channel (Lai et al., 1988; Mignery et al., 1989; Furuichi et al., 1989). There are reasons to suppose that a ryanodine receptor may be present in sea urchin eggs: caffeine and ryanodine, receptor agonists, trigger calcium release from internal stores in the egg (Galione et al., 1991; Sardet et al., 1992; Buck et al., 1992) and a protein that cross-reacts with a ryanodine receptor antibody is present (McPherson et al., 1992). On the other hand, increasing $\left[\mathrm{Ca}_{1}^{2+}\right]$ by microinjection or local application of a calcium ionophore does not trigger calcium release in the sea urchin (Chambers \& Hinckley, 1979; Hamaguchi \& Kuriyama, 1982; Swann \& Whitaker, 1986). This result did not offer much encouragement to the idea of functionally significant ryanodine receptor (RyR)-based CICR in sea urchin eggs, especially when calcium-triggered CICR is easily demonstrated in frog and hamster eggs (Jaffe, 1983; Igusa \& Miyazaki, 1983).

The sulphydryl reagent thimerosal (sodium ethylmercurithiosalicylate) has been shown to cause calcium release from platelets and leucocytes (Hecker et al., 1989; Hatzelman et al., 1990), calcium oscillations in hamster eggs (Swann, 1991) and sensitisation of permeable hepatocytes to $\operatorname{InsP}_{3}$ (Missiaen et al., 1991). We demonstrate here that a latent CICR can be revealed in sea urchin eggs by thimerosal treatment.

\section{Materials and methods}

\section{Obtaining and handling gametes}

Eggs of the sea urchin Lytechinus pictus (Pacific Biomarine Laboratories, Venice, CA) were obtained by injecting females with $0.05 \mathrm{ml} 0.5 \mathrm{M} \mathrm{KCl}$ ]. The jelly coat was removed by passing the eggs through a Nitex mesh and swirling them in artificial seawater (ASW; $488 \mathrm{mM} \mathrm{NaCl}, 40 \mathrm{mM} \mathrm{MgCl}, 10 \mathrm{mM} \mathrm{CaCl}_{2} 10 \mathrm{mM} \mathrm{KCl}$, $2.5 \mathrm{mM} \mathrm{NaHCO}, 1 \mathrm{mM}$ EDTA, pH 8). High calcium (50 mM Ca-ASW) and calcium-free sea waters were made by equimolar substitution of calcium and sodium chloride. Calcium-free sea water contained $2 \mathrm{mM}$ EGTA. The eggs were attached to polylysinecoated coverslips $(0.01 \mathrm{mg} / \mathrm{ml})$ and kept at $16^{\circ} \mathrm{C}$ for all experiments and manipulations. Sperm were collected 'dry' from the males by a similar injection of $\mathrm{KCl}$. They were kept at $4^{\circ} \mathrm{C}$, and when required were diluted in a small volume of sea water some of which was added to the attached eggs, giving $10^{4}-16^{6}$ sperm $/ \mathrm{ml}$ which does not lead to polyspermy.

\section{Measurement of intracellular calcium}

$\left[\mathrm{Ca}_{1}^{2+}\right]$ was measured using the calcium-sensitive fluorescent dyes fura2 or calcium green. The dyes (potassium salts; Molecular Probes, Junction City, OR) were introduced into the eggs by microinjecting them to a final concentration of $10-20 \mu \mathrm{M}$. Using fura2 $\left[\mathrm{Ca}_{1}^{2+}\right]$ in single eggs was determined by a ratiometric method (Swann \& Whitaker, 1986) with acquisition software (UMANS) provided by $\mathrm{Dr}$ C. Reagan of Bio-Rad Ltd. (Hemel Hempstead, UK). Sometimes simultaneous measurements were made of both the $\left[\mathrm{Ca}_{1}^{2+}\right]$ and clamp currents using the UMANS system. Spatial variation in $\left[\mathrm{Ca}_{1}^{2+}\right]$ was monitored and analysed using the calcium green indicator dye and a confocal laser scanning microscopy (CLSM; Leica Lasertechnik, Heidelberg, FRG). The fluorescence signal from the dye reflects both $\left[\mathrm{Ca}_{1}^{2+}\right]$ and dye distribution. We controlled for time-independent inhomogeneities of dye distribution by dividing each image, pixel by pixel, by a reference image taken at the beginning of an experiment. We have not calibrated the resulting ratio images in terms of $\left[\mathrm{Ca}_{1}^{2+}\right]$, but absolute $\left[\mathrm{Ca}_{1}^{2+}\right]$ levels can for the most part be inferred from our whole-cell measurements using fura2.

\section{Electrophysiological recordings}

Microelectrodes were pulled from glass capillary tubing with an inner filament $(1.0 \mathrm{~mm}$ internal diameter; Clarke Electromedical, Pangbourne, UK) using a Kopf Microelectrode Puller (Tujunga, CA). The microelectrodes were filled with $3 \mathrm{M} \mathrm{KC}$ ] and had a resistance of $40-80 \mathrm{M} \Omega$. Electrodes were coupled to a switching single electrode voltage-clamp amplifier, based on the design of Wilson \& Goldner (1975), which can operate in current-clamp and voltageclamp modes. Eggs were first impaled in currentclamp conditions. When required they were then microinjected with a second micropipette which was briefly inserted into the eggs. After removing the pipette only eggs which showed action potentials and which could be clamped at $-70 \mathrm{mV}$ with less than $500 \mathrm{pA}$ of holding current were used. These eggs were voltage clamped at the desired holding potential (David et al., 1988) and subjected to a train of forty $50 \mathrm{mV}$ depolarisations lasting $100 \mathrm{~ms}$ every $5 \mathrm{~s}$ in $50 \mathrm{mM} \mathrm{Ca}$-ASW. The negative capacitance, phase and gain were adjusted to give the best voltage-clamp step (David et al., 1988). For some experiments the eggs were then bathed in sea-water supplemented with 1 $\mathrm{mM}$ thimerosal for $10 \mathrm{~min}$ before return to $50 \mathrm{mM} \mathrm{Ca}$ sea water where a similar train of depolarisations was carried out. Currents and voltages were recorded jointly through a Sony pulse code modulator (model 701-ES) onto a Sony video tape recorder (model EV-C3E), and a Gould chart recorder (model BS-272) and also stored digitally using the UMANS software.

\section{Microinjection}

Eggs were microinjected with solutions containing $10-20 \mathrm{mM}$ fura2 or calcium green, $2 \mu \mathrm{M} \operatorname{InsP}_{3}, 100 \mu \mathrm{M}$ 

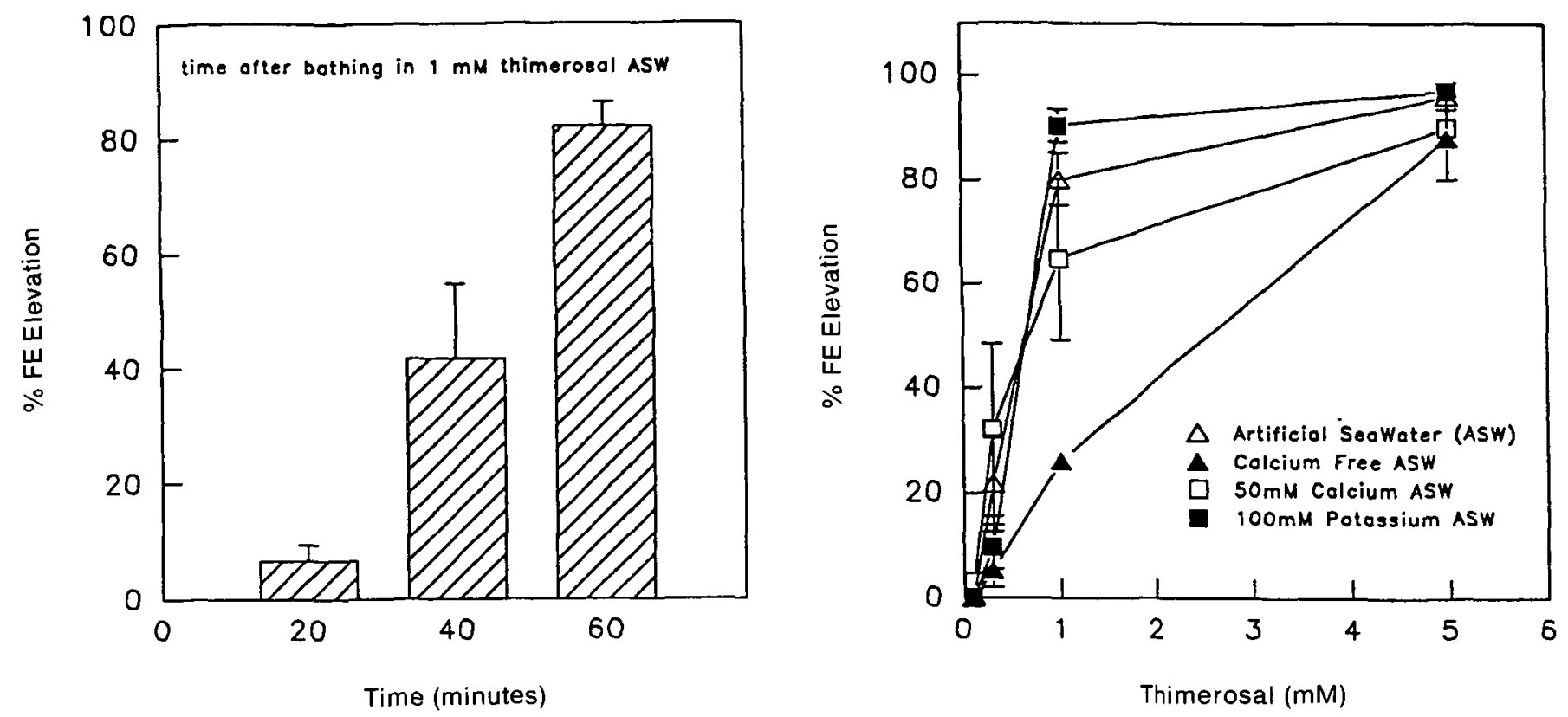

Figure 1(a)
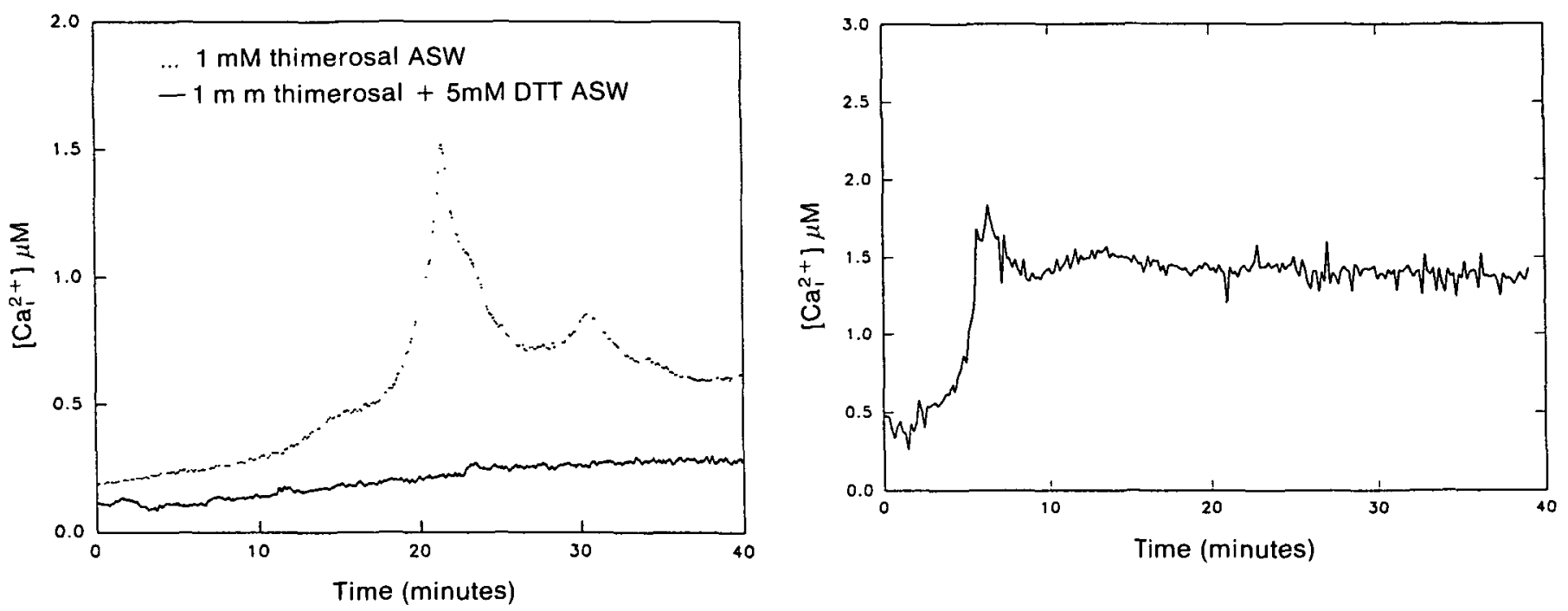

Figure 1(b)

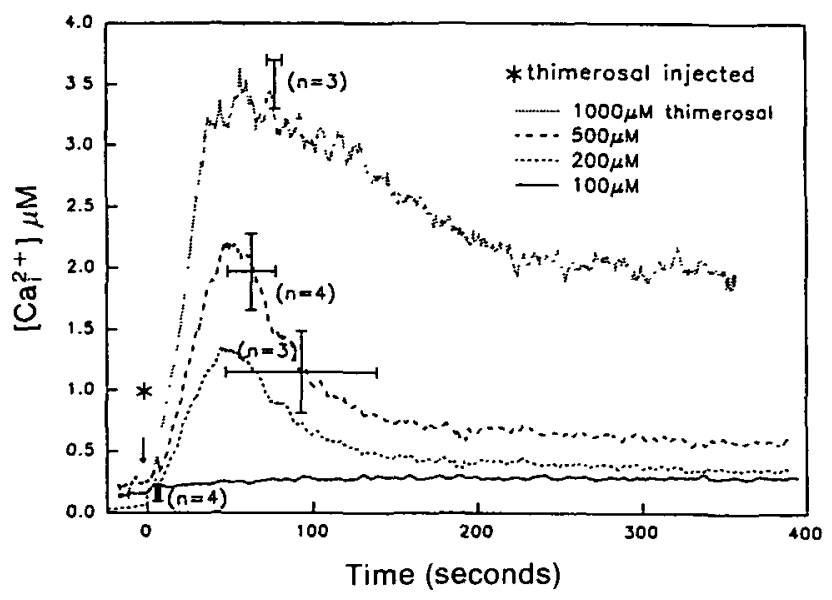

Figure 1(c)

Figure 1 Thimerosal induces egg activation. (a) Eggs were bathed in thimerosal containing ASW and activation assessed by scoring fertilisation envelope (FE) elevation. For ion substitution, calcium or potassium replaced sodium on an isosmolar basis. (b) $\left[\mathrm{Ca}_{1}^{2+}\right]$ measured using the calcium indicator dye fura 2 in single eggs after thimerosal treatment with $1 \mathrm{mM}$ thimerosal in the presence or absence of dithiothreitol (DTT). (c) $\left[\mathrm{Ca}_{1}^{2+}\right]$ in a single egg after thimerosal treatment $(1 \mathrm{mM})$ in calcium-free ASW containing $2 \mathrm{mM}$ EGTA, a calcium chelator. (d) $\left[\mathrm{Ca}_{1}^{2+}\right]$ in single eggs after microinjection of thimerosal to the final concentrations shown. Peak height and time to peak in other experiments are also shown (mean \& SEM, with $n$ in parentheses).

Figure 1(d) 
cADP-ribose (cADPr), $50 \mathrm{mg} / \mathrm{ml}$ heparin and $0.1-1 \mathrm{M}$ thimerosal in $0-500 \mathrm{mM} \mathrm{KCl}$ (adjusted to around 1000 mosmoL/L with $\mathrm{KCl}$ where possible), $20 \mathrm{mM}$ Pipes, at $\mathrm{pH} 6.7$ (adjusted using $\mathrm{KOH}$ ) using pressure pulses (Swann \& Whitaker, 1986).

\section{Source of reagents}

All chemicals were of Analar grade and obtained from DBH (Poole, Dorset, UK); exceptions were: heparin, thimerosal and dithiothreitol (Sigma, Poole, Dorset, $\mathrm{UK}$ ), InsP $\mathrm{P}_{3}$ (Alomone Labs, Shatner Center 3, PO Box 4287, Jerusalem 91042, Israel), cADPr (a gift from A. Galione), and fura2 and calcium green (Molecular Probes, Junction City, OR).

\section{Results}

\section{Thimerosal induces egg activiation}

Bathing unfertilised sea urchin eggs in sea water containing $1 \mathrm{mM}$ thimerosal causes elevation of the fertilisation envelope. The response has a long latency of 20-60 min (Fig. 1a) that is very little affected by altering the external calcium concentration or by depolarising the eggs using $100 \mathrm{mM}$ potassiumcontaining sea water. We measured $\left[\mathrm{Ca}_{1}^{2+}\right]$ using the fluorescent indicator dye fura2. After addition of thimerosal, $\left[\mathrm{Ca}_{1}^{2+}\right]$ increases slowly at first; eventually, the rate of rise increases rapidly and a calcium transient is seen, coincident with FE elevation (Fig. 1b). The peak height of the thimerosal-induced $\left[\mathrm{Ca}_{1}^{2+}\right]$ transient was $1.4 \pm 0.08 \mu \mathrm{M}$ (mean and SEM, $n=4$ ). It occurred $30 \pm 6.5 \mathrm{~min}(n=4)$ after thimerosal addition. Thimerosal also triggered a $\left[\mathrm{Ca}_{1}^{2+}\right]$ transient in eggs bathed in calcium-free sea water containing $2 \mathrm{mM}$ EGTA (Fig. $1 c$ : peak height $1.1 \pm 0.38 \mu \mathrm{M}$ at $34.7 \pm 13.9$ $\min [n=3])$. When eggs were incubated with $1 \mathrm{mM}$ thimerosal in the presence of the sulphydryl reducing agent dithiothreitol (DTT), thimerosal was ineffective (Fig. 1b), suggesting that thimerosal is affecting sulphydryl groups inside the egg.

Others (Hecker et al., 1989; Hatzelman et al., 1990; Swann, 1991; Missiaen et al., 1991) have used thimerosal at lower concentrations than these. To test whether the lower sensitivity of sea urchin eggs to thimerosal might be due to the rate at which it crosses the egg plasma membrane, we microinjected thimerosal directly into the egg cytoplasm. The $\left[\mathrm{Ca}_{1}^{2+}\right]$ response was steeply dependent on the concentration of thimerosal injected (Fig. 1d). Eggs showed no immediate response to thimerosal injected to a final concentration of $100 \mu \mathrm{M}$, but $200 \mu \mathrm{M}$ thimerosal elicited a $\left[\mathrm{Ca}_{1}^{2+}\right]$ transient that rose to $2 \mu \mathrm{M}$, similar to the increase seen at fertilisation. Microinjection of $1 \mathrm{mM}$ thimerosal caused a very large increase in $\left[\mathrm{Ca}_{i}^{2+}\right]$,
Table 1 The fertilisation calcium transient in thimerosal-treated eggs

\begin{tabular}{|c|c|c|c|}
\hline & $\begin{array}{l}\text { Response latency } \\
\text { (s) }\end{array}$ & $\begin{array}{l}\text { Time to peak } \\
\text { (s) }\end{array}$ & $\begin{array}{l}\text { Peak height } \\
(\mu \mathrm{M})\end{array}$ \\
\hline Controls & $26.5 \pm 1.9(22)$ & $29.4 \pm 1.3(31)$ & $.10(19)$ \\
\hline \multicolumn{4}{|c|}{ Thimerosal-treated } \\
\hline Type 1 & $19.0 \pm 1.6(15)^{a}$ & $20.0 \pm 0.8(15)^{b}$ & $1.8 \pm 0.17(15)$ \\
\hline Type 2 & $0 \quad(8)^{b}$ & $18.9 \pm 2.5(8)^{b}$ & $1.6 \pm 0.24(8)$ \\
\hline
\end{tabular}

Mean and SEM are shown, with $n$ in parentheses.

Time to peak is measured from the just-noticeable onset of the calcium transient to its paek. It is equivalent to the transit time of the fertilisation calcium wave across the egg.

a Significantly different from controls (one-tailed $t$-test), $p<0.05$.

${ }^{b}$ Significantly different from controls (one-tailed $t$-test), $p<0.001$.

three to four times larger than a fertilisation $\left[\mathrm{Ca}_{1}^{2+}\right]$ transient, implying perhaps that the calcium store is not fully emptied at fertilisation, or again, that thimerosal may mobilise calcium stores not accessible to fertilisation messengers. These data indicate that thimerosal can trigger release of calcium from the internal calcium store in sea urchin eggs and give rise to a calcium transient that resembles the fertilisation calcium response and that the cytoplasmic concentration of thimerosal determines both the magnitude and the latency of the response.

\section{Thimerosal decreases the latency of the fertilisation response}

Unfertilised eggs microinjected with fura2 were bathed in $1 \mathrm{mM}$ thimerosal sea water and fertilised. The resulting increase in $\left[\mathrm{Ca}_{1}^{2+}\right]$ was similar in magnitude to controls but had a more rapid rising (Table 1) and falling phase (Fig. 2a). The earliest phase of the response showed one of two patterns. In the first type of response $(15 / 23 ; 65 \%)$ an initial increase in $\left[\mathrm{Ca}_{i}^{2+}\right]$ was followed $10 \mathrm{~s}$ or so later by the larger fertilisation calcium transient (Fig. $2 b$ ). In the second type of response $(8 / 23 ; 35 \%)$ no initial increase was detected prior to the calcium transient (Fig. 2b.) The small initial increase is seen in control eggs at fertilisation (Fig. 2b) and appears to represent calcium influx through voltage-gated calcium channels (Whitaker et al., 1989); Crossleyet al., 1991; see Fig. 4). The calcium influx is due to a calcium action potential that occurs when the egg depolarises at the time of sperm-egg fusion (Whitaker \& Swann, 1993); the latency of the fertilisation calcium transient (the latent period) can be taken as the time from the initial calcium step to the beginning of the transient (Crossley et al., 1991). Table 1 shows that thimerosal treatment reduces the latent period (type 1) responses) and may abolish it (type 2 responses). 


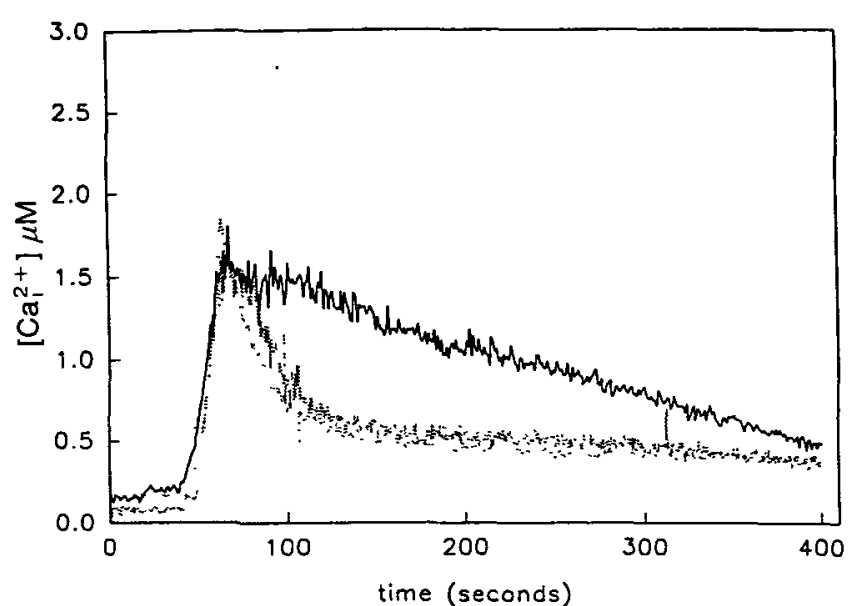

(a)

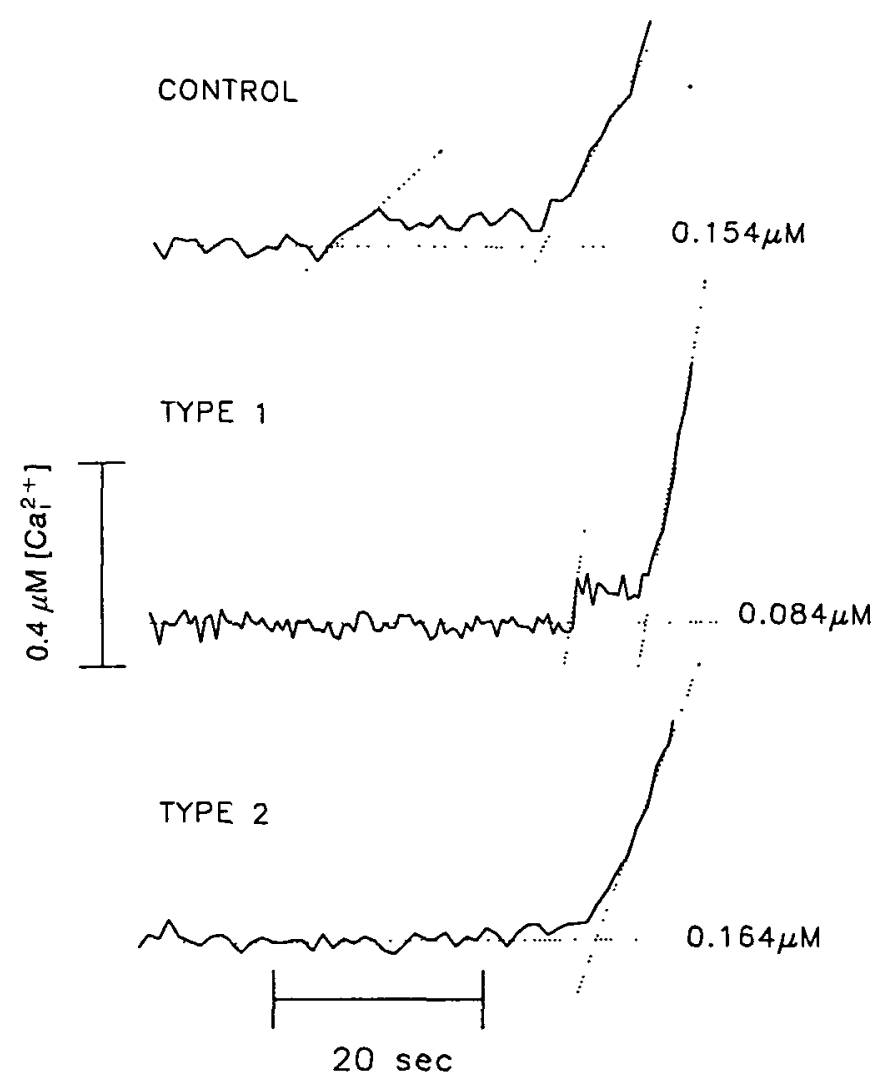

(b)

Figure 2 The fertilisation $\left[\mathrm{Ca}_{1}^{2+}\right]$ transient in control and thimerosal-treated eggs. (a) $\left[\mathrm{Ca}_{1}^{2+}\right]$ in single eggs at fertilisation. A control record is shown as a continuous line. Two transients from thimerosal-treated ( $1 \mathrm{mM}$ for $10 \mathrm{~min})$ eggs are also shown. (b) From the same experiments and showing the small, early increase in $\left[\mathrm{Ca}_{i}^{2+}\right]$ that marks the beginning of the latent period. The dotted lines emphasise the step increase. The type 1 response has an early step similar in magnitude to the controls; the latency of the response is reduced. The type 2 response lacks the early increase in $\left[\mathrm{Ca}_{1}^{2+}\right]$ : the latent period is abolished. The records are representative of the experiments summarised in Table 1.
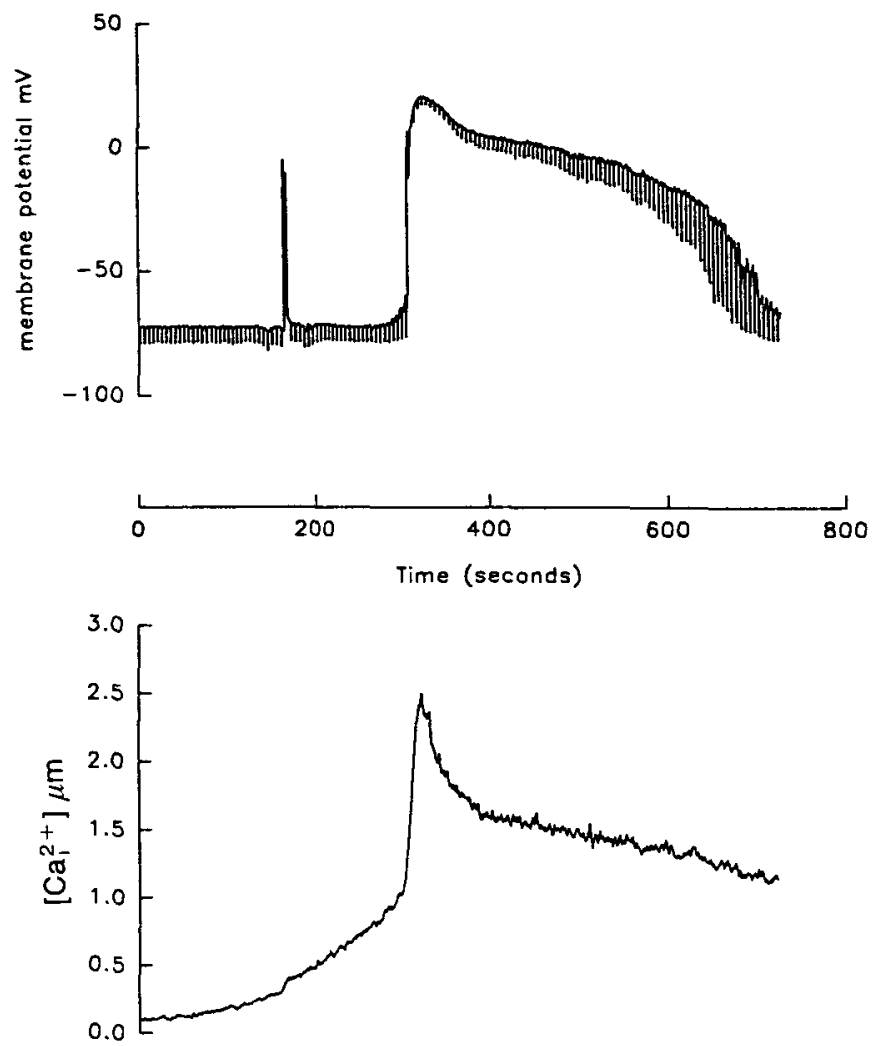

Figure 3 Calcium action potentials in a thimerosal-treated egg. Simultaneous records of membrane potential and $\left[\mathrm{Ca}_{1}^{2+}\right]$ in an egg in $50 \mathrm{mM}$ calcium ASW treated with $1 \mathrm{mM}$ thimerosal for $10 \mathrm{~min}$ prior to the recording. Constant hyperpolarising current pulses monitor egg membrane resistance. At around $180 \mathrm{~s}$ a single depolarising current pulse was applied to evoke an action potential. The action potential caused an immediate, though small, increase in $\left[\mathrm{Ca}_{1}^{2+}\right]$, followed by a slower increase to around $1 \mu \mathrm{M}$. At this point, the egg spontaneously depolarised and fired a second action potential. The second action potential evoked a very rapid increase in $\left[\mathrm{Ca}_{1}^{2+}\right]$, to $2.5 \mu \mathrm{M}$, due to CICR.

Of course, the lack of depolarisation-induced calcium entry might trivially be due to inactivation of the voltage-dependent calcium channel in thimerosaltreated eggs. This is not the case. Fig. 3 shows an experiment in which membrane potential and $\left[\mathrm{Ca}_{1}^{2+}\right]$ were recorded simultaneously in a thimerosal-treated egg. Depolarisation of the egg triggers an action potential. The calcium action potential (Chambers and de Armendi, 1979) is immediately followed by a step $\left[\mathrm{Ca}_{1}^{2+}\right]$ increase, after which $\left[\mathrm{Ca}_{1}^{2+}\right]$ rises more steeply. A second, spontaneous action potential then triggers a large $\left[\mathrm{Ca}_{1}^{2+}\right]$ transient. This experiment indicates that calcium influx can trigger a full-blown $\left[\mathrm{Ca}_{1}^{2+}\right]$ transient in thimerosal-treated eggs and that the type 2 responses we observed at fertilisation might be due to depolarisation-induced calcium entry, a pure form of CICR. 


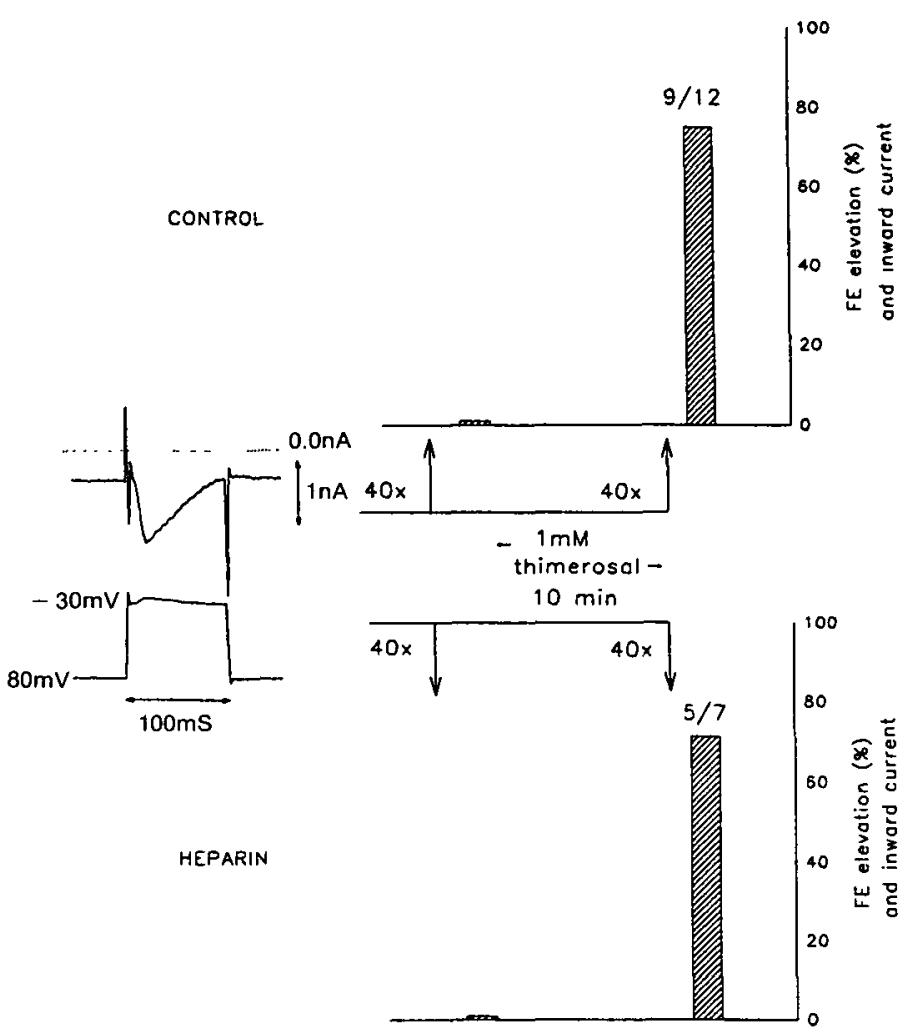

Figure 5(a)

\section{Depolarisation-induced calcium influx}

We measured the depolarisation-induced calcium influx using confocal microscopy. Depolarisation of unfertilised voltage-clamped sea urchin eggs triggers the voltage-gated calcium current (David et al., 1988). Fig. 4(a) (facing page) shows that the increase in $\left[\mathrm{Ca}_{i}^{2+}\right]$ after a single depolarising step in a voltage-clamped sea urchin egg is modest and initially confined to the region just beneath the plasma membrane. The increase is comparable to the initial $\left[\mathrm{Ca}_{i}^{2+}\right]$ increase at fertilisation (Fig. $4 b$, facing page) and is absent when eggs are fertilised in calcium-free sea water or in sea water containing the calcium channel blocker diltiazam, confirming our previous suggestions that the initial increase is due to voltage-gated calcium influx.

\section{Sensitisation to depolarisation-induced CICR}

Although the calcium current rapidly inactivates at positive membrane potentials (David et al., 1988), repeated depolarisation at $5 \mathrm{~s}$ intervals generates repeated calcium currents of similar magnitude (1-2 $\mathrm{nA}$ ). Fig. 5(a) shows that calcium influx due to repeated depolarisation does not itself trigger a calcium wave. However, if eggs are pre-treated with $1 \mathrm{mM}$ thimerosal, a train of 40 depolarising pulses causes a Ca $\mathrm{a}_{\mathrm{i}}$-activated cation conductance (David et al., 1988) and a fertilisation envelope to develop. These two events always coincide with the activating
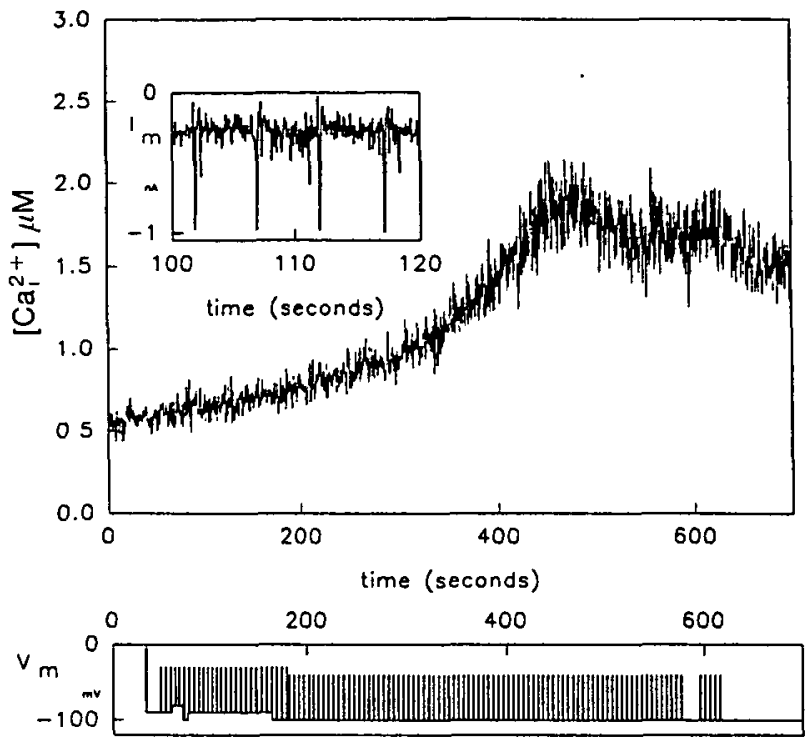

(b)

Figure 5 Calcium transients evoked by repetitive depolarisation in voltage-clamped sea urchin eggs. (a) Voltageclamped sea urchin eggs in $50 \mathrm{mM}$ calcium ASW were held at $-80 \mathrm{mV}$ and 40 successive depolarisation steps of $0.1 \mathrm{~s}$ duration to $-30 \mathrm{mV}$ were applied every $5 \mathrm{~s}$. The depolarising steps triggered an inactivating inward calcium current (inset left: see David et al., 1988). This did not lead to egg activation. The eggs were then treated with $1 \mathrm{mM}$ thimerosal for $10 \mathrm{~min}$ in normal ASW, before applying the same voltage protocol a second time in $50 \mathrm{mM}$ calcium ASW. Mean inward current was $1.7 \pm 0.2 \mathrm{nA}$ (mean and SEM, $n=12$ ) and did not alter significantly after thimerosal treatment. The second train of depolarisation led to fertilisation envelope (FF) elevation and the activation of the $\mathrm{Ca}_{1}$-dependent inward cation current (not shown). Each experiment involved a single egg. The cumulative results are shown. The experiments were also carried out after microinjection of $250 \mu \mathrm{g} / \mathrm{ml}$ heparin (mean inward current: $1.1 \pm 0.3 \mathrm{nA}$ ). The results were similar. (b) $\left[\mathrm{Ca}_{1}^{2+}\right]$ in a single voltageclamped sea urchin egg measured using fura2. The train of depolarising pulses $(0.5 \mathrm{~s}$ duration, $0.2 \mathrm{~Hz})$ caused inward calcium currents (inset) and led to a $\left[\mathrm{Ca}_{1}^{2+}\right]$ transient.

calcium wave at fertilisation, again implying that the calcium wave can be triggered by calcium influx in thimerosal-treated eggs. Activation is unaffected by prior microinjection of heparin, an $\mathrm{InsP}_{3}$ receptor (InsP $\mathrm{P}_{3} \mathrm{R}$ ) antagonist (Hill et al., 1987; Fig. 5a). We measured $\left[\mathrm{Ca}_{1}^{2+}\right]$ in thimerosal-treated eggs under these conditions and found that the train of depolarising pulses caused $\left[\mathrm{Ca}_{i}^{2+}\right]$ to increase until it generated a regenerative increase in $\left[\mathrm{Ca}_{1}^{2+}\right]$ (Fig. b). Thimerosal treatment evidently sensitises a CICR mechanism in the egg that is unaffected by an $\mathrm{InsP}_{3}$ antagonist.

\section{Sensitisation to InsP $P_{3}, c A D P r$ and calcium injection}

Thimerosal and other sulphydryl oxidixing agents have been shown to sensitise both Ins $\mathrm{P}_{3} \mathrm{R}$ (Finch et al., 


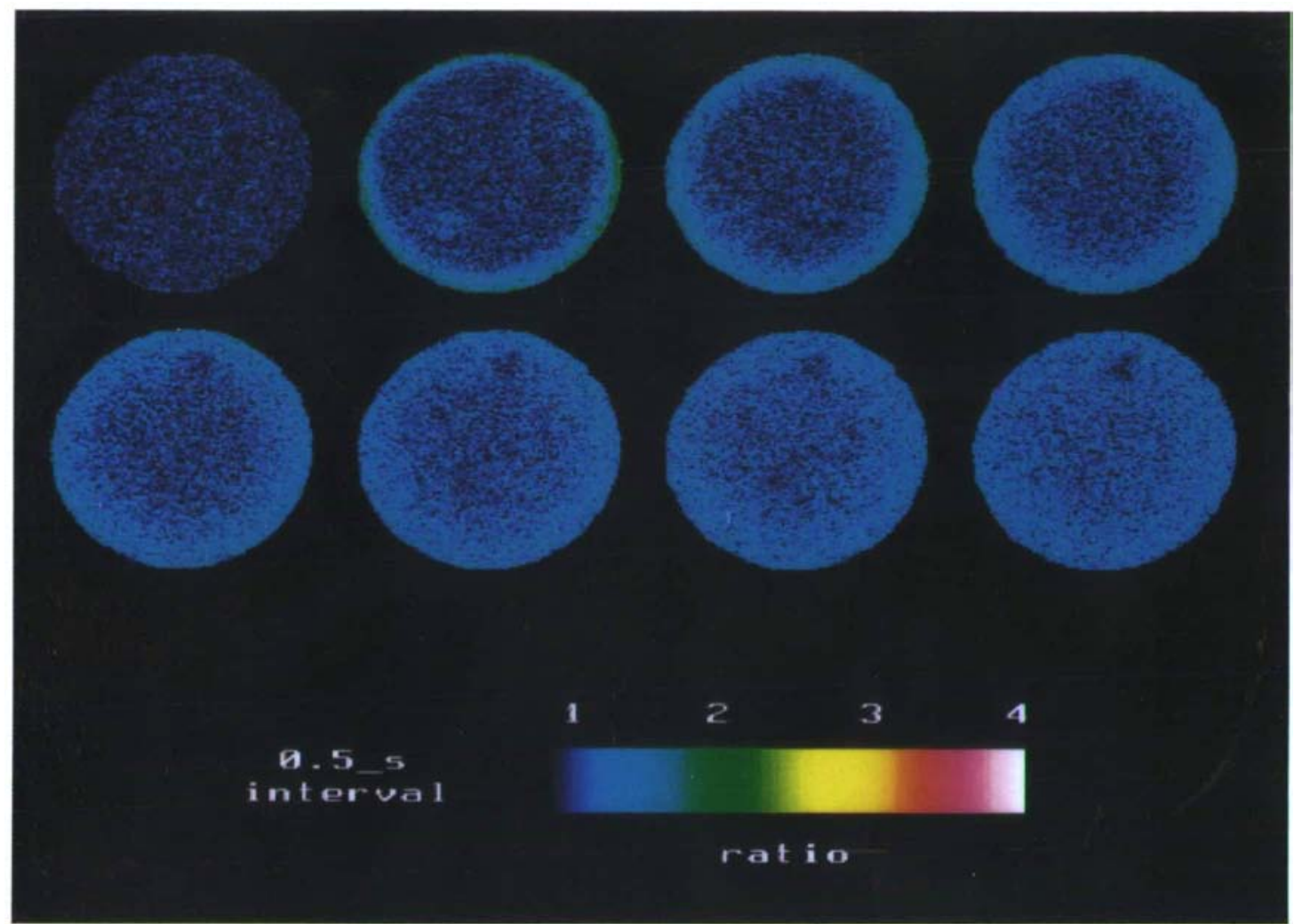

(b)

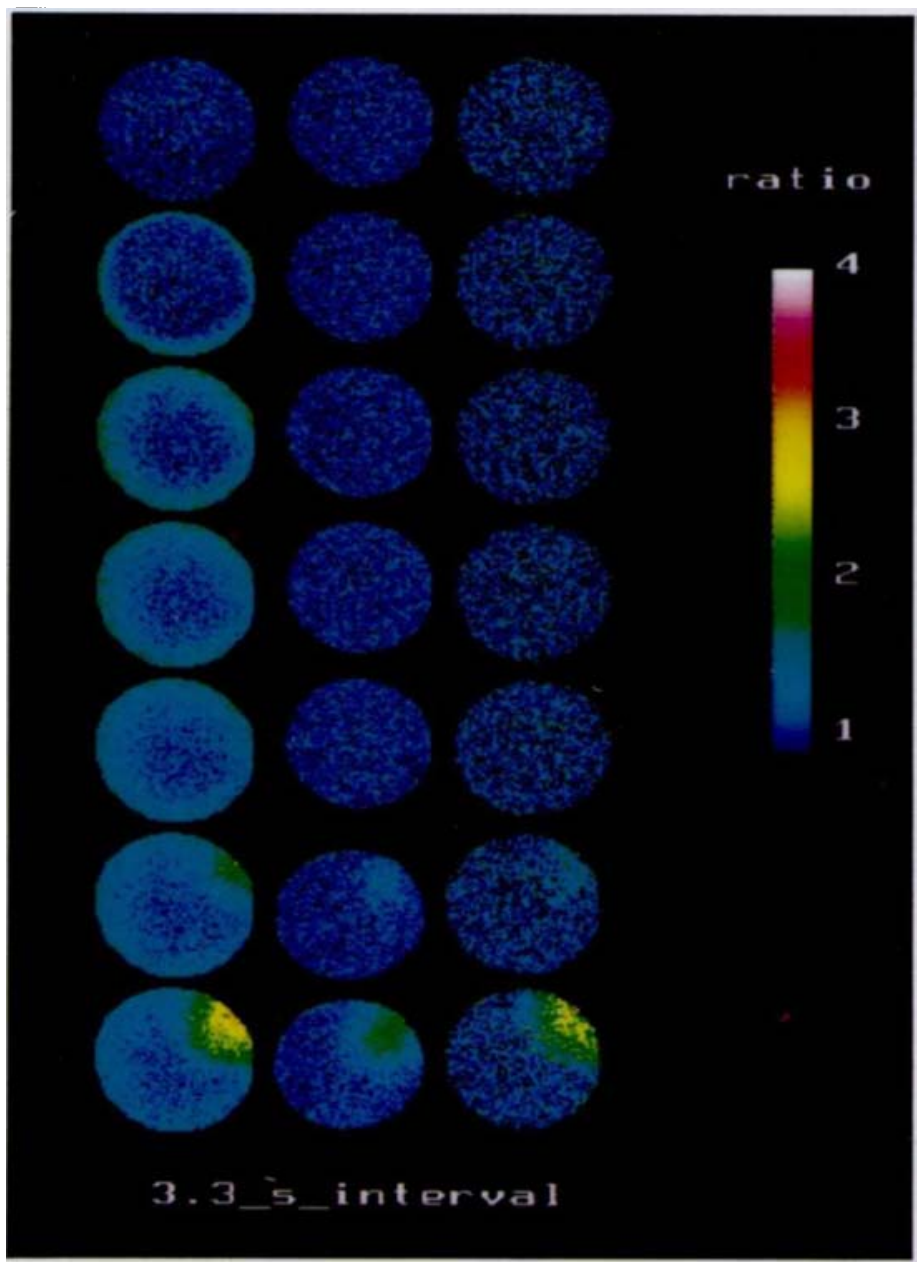

Figure 4 Spatial $\left[\mathrm{Ca}_{1}^{2+}\right]$ distribution during depolarisation-induced calcium influx in $50 \mu \mathrm{M} \mathrm{Ca-ASW}$ : confocal ratio imaging of $\left[\mathrm{Ca}_{1}^{2+}\right]$ using the calcium indicator dye calcium green. (a) An egg under voltage clamp. The egg membrane was depolarised with a $60 \mathrm{mV}$ step for $0.5 \mathrm{~s}$ from a $-80 \mathrm{mV}$ holding potential between the first and second image (the images read from left to right in two rows). The resulting calcium inward current $(1 \mathrm{nA}$, not shown) leads to an increase in $\left[\mathrm{Ca}_{1}^{2+}\right]$ just beneath the plasma membrane. During the $3 \mathrm{~s}$ period shown, calcium diffuses towards the centre of the egg. (b) The voltagegated calcium influx at fertilisation in 3 eggs. Each experiment reads vertically from top to bottom. The leftmost set of images shows the calcium influx in control eggs at the beginning of the latent period. The latent period ends with the initiation of the fertilisation calcium wave in the final two images. The latent period was $13 \pm$ $0.8 \mathrm{~s}(n=9)$ in these experiments, suggesting that the confocal technique can detect the localised initiation of the fertilisation wave earlier than the whole cell fluorescence technique. Wave transit time was $24.9 \pm 1.8 \mathrm{~s}$ $(n=9)$. The centre column illustrates the consequences of adding the calcium channel blocker diltiazam $(150 \mu \mathrm{M})$ to the sea water before fertilisation: the initial ring of influx is absent and the fertilisation wave begins in the last two images. The rightmost column shows fertilisation in calcium-free sea water. Again, the calcium influx component is missing, but the fertilisation wave initiates as in controls; wave propagation time was $23.0 \pm 0.98 \mathrm{~s}$ $(n=5)$. The control record is representative of 9 experiments. The experimental data are representative of 2 experiments with diltiazam and 5 in calcium-free sea water. Eggs were fertilised in calcium-free sea water using sperm that had been triggered to undergo the acrosome reaction by treatment with egg jelly.

(Facing p.40) 

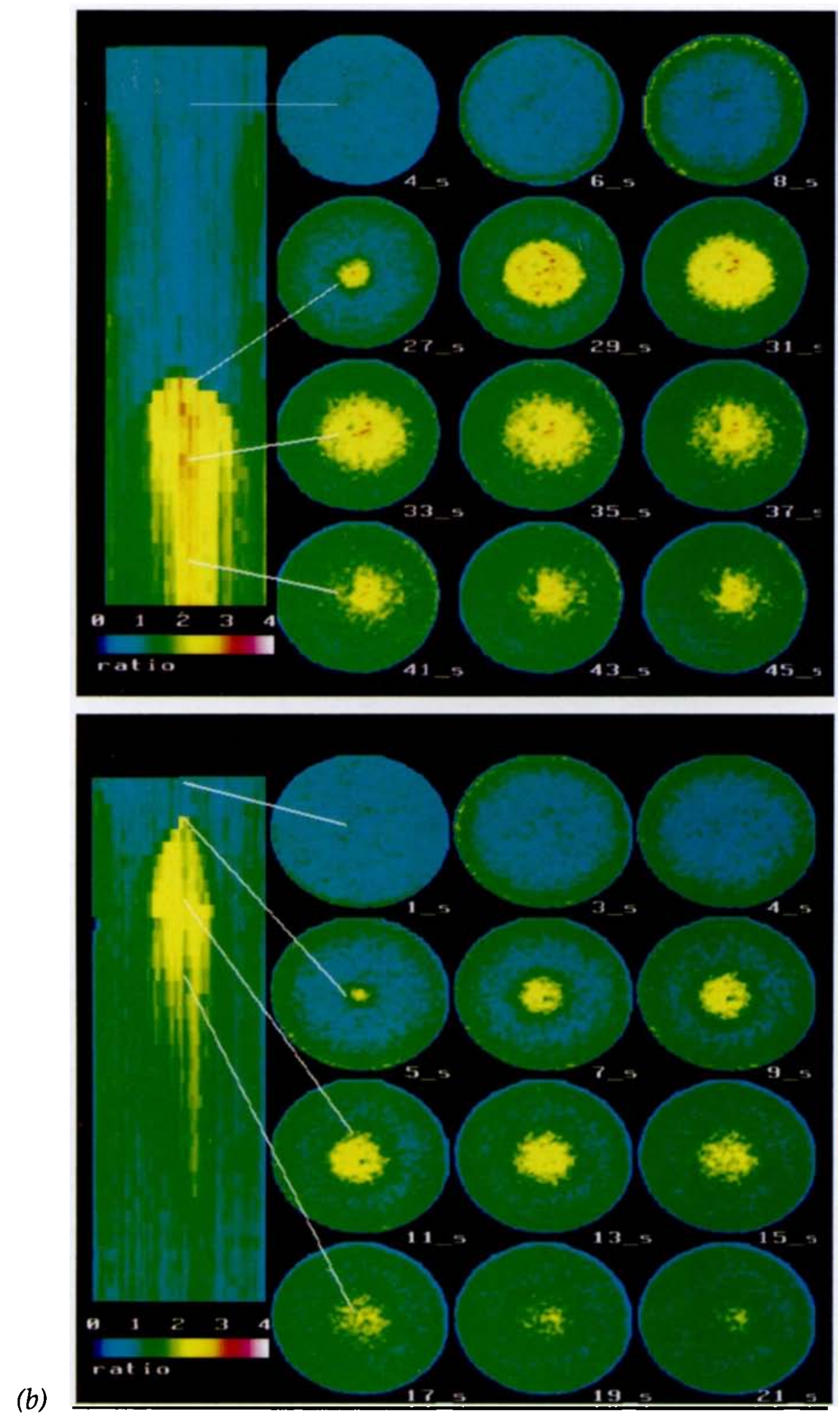

Figure $6(b)$ Confocal images of $\left[\mathrm{Ca}_{\mathrm{i}}^{2+}\right]$ in single sea urchin eggs during microinjection of calcium. The upper image shows a control egg, the lower image an egg previously treated for $10 \mathrm{~min}$ with $1 \mathrm{mM}$ thimerosal. In both experiments illustrated, inserting the microinjection pipette caused the egg to depolarise and fire a calcium action potential, the effects of which are seen as a peripheral increase in the ratio dye signal. Calcium microinjection in both cases caused a local increase at the site of injection that subsided gradually as the injected calcium was sequestered. In neither case did a calcium wave spread in the egg, though we estimate that $\left[\mathrm{Ca}_{\mathrm{i}}^{2+}\right]$ reached $1 \mu \mathrm{M}$ locally. The bar to the left of the figure plots the ratio signal across a horizontal line through the egg equator with time, which progresses downwards. Lines indicate the relation between the equatorial line time series and the equatorial slice time series. 

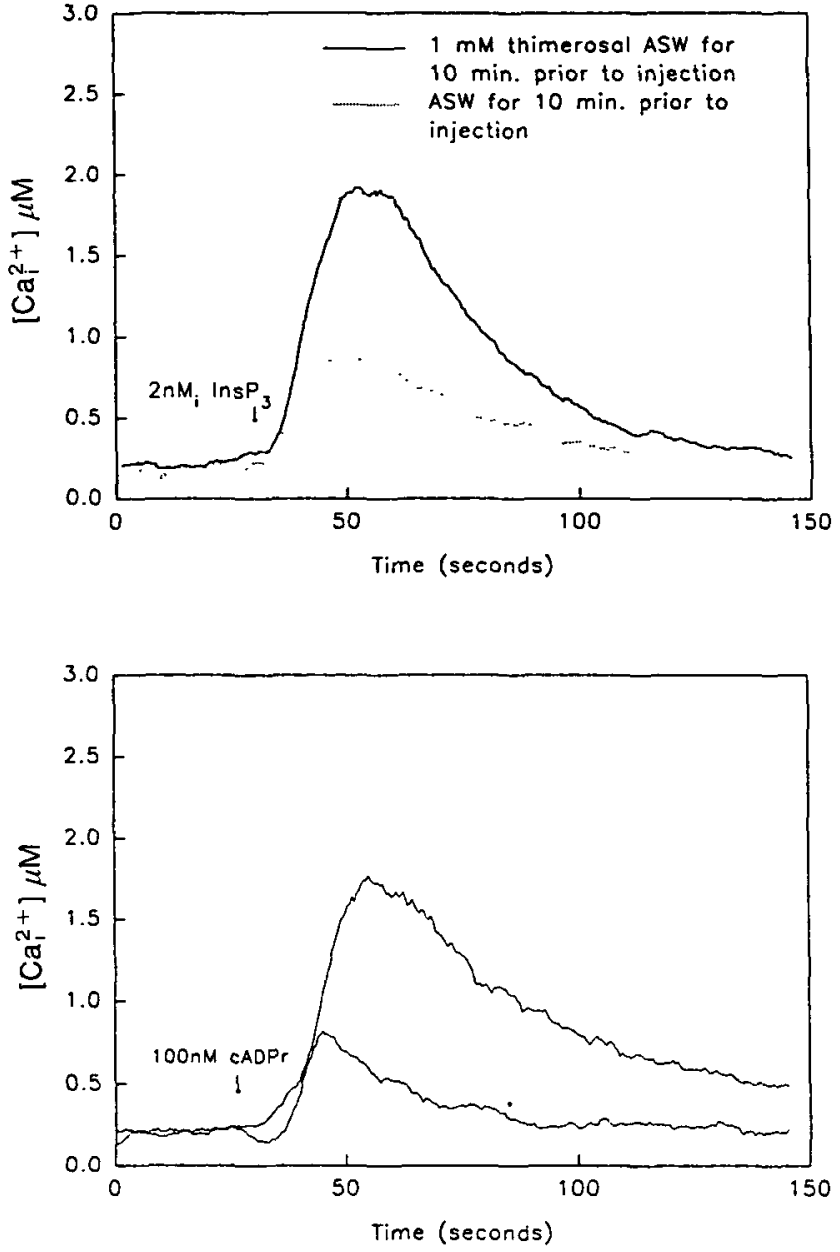

(a)

Figure 6 Effect of thimerosal on sensitivity to $\operatorname{InsP}_{3}, \mathrm{cADPR}$ and calcium microinjection. (a) Comparison of effects on InsP $_{3}$ and cADPr to a final concentration of $2 \mathrm{nM}$ in control and thimerosal-treated ( $1 \mathrm{mM}$ thimerosal for $10 \mathrm{~min}$ ) eggs. The effects of both are potentiated by thimerosal pretreatment. For Ins $\mathrm{P}_{3}$, peak $\left[\mathrm{Ca}_{1}^{2+}\right]$ was $0.23 \pm 0.03 \mu \mathrm{M}(n=)$ in control eggs and $1.12 \pm 0.13 \mu \mathrm{M}(n=3)$ after thimerosal, and for cADPr the respective values were $0.54 \pm 0.05(n=6)$ and $1.13 \pm 0.20(n=6)$. The differences between controls and experiments were significantly different in a one-tailed t-test: Ins $\mathrm{P}_{3}, p<0.001$; cADPr, $p<0.02(b)$ See facing page.

1991) and RYR (Islam et al., 1992). We looked for sensitising effects on both release channel types by microinjecting their specific agonists $\mathrm{InsP}_{3}$ and $\mathrm{cADPr}$ (Lee et al., 1989; Galione et al., 1991; Galione, 1992). There was a small degree of sensitisation to both compounds (Fig. 6a), comparable to that described earlier for InsP $_{3} \mathrm{R}$ (Missiaen et al., 1991). We also microinjected calcium itself, to provoke a pure CICR. We saw no CICR in control eggs (Fig. 6b, facing page) but, to our surprise, we saw no CICR in response to calcium injection in thimerosal-treated eggs either, despite local increases in calcium that reached micromolar levels - much higher than the modest increase recorded after depolarisation-induced calcium entry.

\section{Discussion}

We show that a large, fertilisation-like calcium transient can be triggered in unfertilised thimerosal-treated sea urchin eggs by increasing $\left[\mathrm{Ca}_{i}^{2+}\right]$. We find that thimerosal sensitizes the Ins $P_{3} R$ to InsP $P_{3}$, and the RYR to its putative agonist, cADPr. Thimerosal appears to affect both calcium release channel types. There is little, if any, sensitisation of the egg to microinjected calcium ions. At higher concentrations than those required to sensitise CICR, thimerosal itself can cause a calcium transient. Although the thimerosal-induced $\left[\mathrm{Ca}_{\mathrm{i}}^{2+}\right]$ transient may coincide with rapid calcium influx, it can also occur in the complete absence of extracellular calcium.

Thimerosal treatment sensitises a CICR mechanism in the unfertilised sea urchin egg. In treated eggs, calcium influx triggers a full-blown $\left[\mathrm{Ca}_{1}^{2+}\right]$ transient, in marked contrast to untreated eggs where CICR cannot be demonstrated by any means (Chambers \& Hinckley, 1979; Hamaguchi \& Kuriyama, 1982; Swann \& Whitaker, 1986). Thimerosal treatment reveals a latent CICR mechanism that is not sensitive to heparin, an $\mathrm{Ins}_{3} \mathrm{R}$ antagonist.

Thimerosal also reduces or abolishes the latency of the fertilisation response and increases the velocity of the fertilisation calcium wave. The reduction in latency and increase in propagation velocity (rate of rise) are presumably due to the sensitisation of a CICR mechanism. Though these data do not tell us whether CICR operates during the normal fertilisation $\left[\mathrm{Ca}_{1}^{2+}\right]$ wave, they do at least increase the chances that it may. We also show that the fertilising sperm triggers a calcium influx through voltage-gated calcium channels that leads to an early increase in $\left[\mathrm{Ca}_{1}^{2+}\right]$ just beneath the plasma membrane. The abolition of the latent period at fertilisation in a significant proportion of thimerosal-treated eggs is presumably due to the immediate triggering of CICR by voltage-gated calcium influx.

The most remarkable feature of thimerosalsensitised CICR in sea urchin eggs is the disparity betwen the efficacy of calcium influx and calcium microinjection as a trigger. Calcium injections that led to larger and more extensive elevations of $\left[\mathrm{Ca}_{i}^{2+}\right]$ than calcium influx were completely ineffective as CICR triggers. It may be that the relative potency of calcium influx as a trigger to thimerosal-sensitised CICR is due to the presence of RYR just beneath the plasma membrane (McPherson et al., 1992).

\section{Acknowledgements}

We thank Michael Aitchison for preparing figures. This work was supported by the Wellcome Trust, the 
Royal Society and the Science and Engineering Research Council. A.M. was an SERC scholar. I.G. has a fellowship from the Ministère de la recherche.

\section{References}

Berridge, M.J. \& Galione, A. (1988). Cytosolic calcium oscillators. FASEB J. 2, 3074-82.

Bezprovzanny, I., Watras, J. \& Erlich, B.E. (1991). Bell-shaped calcium response of $\operatorname{Ins}(1,4,5) \mathrm{P}_{3^{-}}$and calcium-gated channels from endoplasmic reticulum. Nature 351, 751-4.

Buck, R.W., Rakow, T.L. \& Shen, S.S. (1992). Synergistic release of calcium in sea urchin eggs by caffeine and ryanodine. Exp. Cell Res. 202, 59-66.

Chambers, E.L. \& de Armendi, J. (1979). Membrane potential, action potential and activation potential of the eggs of the sea urchin Lytechinus variegatus. Exptl Cell Res. 126, 333-342.

Chambers, E.L. \& Hinckley, R.E. (1979). Non-propagative cortial reactions induced by the divalent ionophore A23187 in the eggs of the sea urchin Lytechninus variegatus. Exp. Cell Res. 124, 441-6.

Ciapa, B., Borg, B. \& Whitaker, M.J. (1992). Polyphosphoinositide metabolism during the fertilization wave in sea urchin eggs. Development 115, 187-95.

Crossley, I., Whalley, T. \& Whitaker, M.J. (1991). Guanosine 5-thiotriphosphate may stimulate phophoinositide messenger production in sea urchin eggs by a different route than the fertilizing sperm Cell Regulation 2, 121-33.

David, C., Halliwell, J. \& Whitaker, M.J. (1988). Some properties of the membrane currents underlying the fertilization potential in sea urchin eggs. J. Physiol. (Lond.) 402, 139-54.

Endo, M. (1977). Calcium release from the sarcoplasmic reticulum. Physiol. Rev. 57, 71-108.

Fabiato, A. (1985). Stimulated calcium current can both cause calcium loading in and trigger calcium release from the sarcoplasmic reticulum of a skinned cardiac Purkinje cell. J. Gen. Physiol. 85, 291-320.

Finch, E.A., Turner, T.J. \& Goldin, S.M. (1991). Calcium as a coagonist of inositol 1,4,5-triphosphate induced calcium release. Science 252, 443-6.

Furuichi, T., Yoshikawa, S., Miyawaki, A., Wada, K., Maeda, N. \& Mikoshiba, K. (1980). Primary structure and functional expression of the inositol 1,4,5-trisphosphatebinding protein P400. Nature 342, 32-8.

Galione, A. (1992). Calcium-induced calcium release and its modulation by cyclic ADP-ribose. Trends Pharmacol. Sci. 13, 304-6.

Galione, A., Lee, H.C. \& Busa, W.B. (1991). $\mathrm{Ca}^{2+}$-induced $\mathrm{Ca}^{2+}$ release in sea urchin egg homogenates: modulation by cyclic ADP-ribose. Science 253, 1143-6.

Hamaguchi, Y. \& Kuriyama, R. (1982). Aster formation in sand dollar eggs by microinjection of calcium buffers. Exptl Cell Res. 141, 450-454.

Hatzelman, A., Haurand, M. \& Ullrich, V. (1990). Involvement of calcium in the thimerosal-stimulated formation of leukotriene by AMLP in human polymorphonuclear leukocytes. Biochem. Pharmacol. 39, 559-67.

Hecker, M., Brüner, B., Decker, K. \& Ullrich, V. (1989). The sulphydryl reagent thimerosal elicits human platelet aggregation by mobilization of intracellular calcium and secondary prostaglandin endoperoxide formation. Biochem. Biophys. Res. Commun. 159, 961-8.
Hill, T.D., Berggren, P. \& Boynton, A.L. (1987). Heparin inhibits inositol trisphosphate-induced calcium release from permeabilized rat liver cells. Biochem. Biophys. Res. Commun. 149, 870-901.

Igusa, Y. \& Miyazaki, S. (1983). Effects of altered extracellular and intracellular calcium concentration on hyperpolarizing responses of hamster egg. J. Physiol. (Lond.) 340, 611-32.

Islam, M.S., Rorsman, P.\& Beggren, P.O. (1992). $\mathrm{Ca}^{2+}$-induced $\mathrm{Ca}^{2+}$-release in insulin secreting cells. FEBSLett.296,287-91.

Jacob, R. (1990). Calcium oscillations in electrically nonexcitable cells. Biochim. Biophys. Acta 1052, 427-58.

Jaffe, L.F. (1983). Sources of calcium in egg activation: a review and hypothesis. Dev. Biol. 99, 256-76.

Kacser, H. (1955). The cortical changes on fertilization in the sea urchin egg. J. Exp. Biol. 32, 451-67.

Lai, F.A., Erickson, H.P., Rousseau, E., Lin, Q.Y. \& Meissner, G. (1988). Purification and reconstitution of the calciumrelease channel from skeletal muscle. Nature 331, 315-19.

Lee, H.C., Walseth, T.F., Bratt, G.T., Hayes, R.N. \& Clapper, D.L. (1989). Structural determination of a cyclic metabolite of $\mathrm{NAD}^{+}$with intracellular $\mathrm{Ca}^{2+}$-mobilizing activity.J. Biol. Chem. 264, 1608-15.

McPherson, S.M., McPherson, P.S., Matthews, L., Campbell, K.P. \& Longo, F.J. (1992). Cortical localization of calcium release channel in sea urchin eggs. J. Biol. 116. 1111-21.

Meyer, T. \& Stryer, L. (1988). Molecular model for receptorstimulated calcium spiking. Proc. Natl. Acad. Sci. USA 85, 5051-5.

Mignery, G.A., Südhof, T.C., Takei, K. \& De Camilli, P. (1989). Putative receptor for inositol, 1,4,5-trisphosphate similar ryanodine receptor. Nature 342, 192-5.

Missiaen, L., Taylor, C.W. \& Berridge, M.J. (1991). Spontaneous calcium release from inositol trisphosphatesensitive calcium stores. Nature 352, 241-2.

Miyazaki, S., Yuzaki, M., Nakada, K., Shirakawa, H., Nakanishi, S., Nakade, S. \& Mikoshiba, K. (1992). Block of $\mathrm{Ca}^{2+}$ wave and $\mathrm{Ca}^{2+}$ oscillation by antibody to the $\mathrm{IP}_{3}$ receptor in fertilized hamster eggs. Science 257, 251-5.

Sardet, C., Gillot, I., Ruscher, A., Payan, P., Girard, J.-P. \& de Renzis, G. (1992). Ryanodine activates sea urchin eggs. Devl. Growth Differ. 34, 37-42.

Swann, K. (1991). Thimerosal causes calcium oscillations and sensitizes calcium-induced calcium release in unfertilized hamster eggs. FEBS Lett. 278, 175-178.

Swann, K.S. \& Whitaker, M.J. (1986). The part played by inositol trisphosphate and calcium in the propagation of the fertilization wave in sea urchin eggs. J. Cell Biol. 103, 2333-42.

Turner, P.R., Sheetz, M.P. \& Jaffe, L.A. (1984). Fertilization increases the polyphosphoinositide content of sea urchin eggs. Nature 310, 414-15.

Whitaker, M.J. \& Aitchison, M.J. (1985). Calcium-dependent polyphosphoinositide hydrolysis is associated with exocytosis in vitro. FEBS Lett. 182, 119-24.

Whitaker, M.J. \& Irvine, R.F. (1984). Micro-injection of inositol trisphosphate activates sea urchin eggs. Nature 312, 636-8.

Whitaker, M.J. \& Swann, K. (1993). Lighting the fuse at fertilization. Development 117, 1-12.

Whitaker, M.J., Swann, K. \& Crossley, I.B. (1989). What happens during the latent period at fertilization in sea urchin eggs. In: Mechanisms of Egg Activation, ed. R. Nuccitelli, pp. 159-63. New York: Plenum Press.

Wilson, W.A. \& Goldner, M.M. (1975). Voltage clamping with a single microelectrode. J. Neurobiol. 6, 411-22. 